\title{
Influence of Pacing Mode and Rate on Peripheral Levels of Atrial Natriuretic Peptide (ANP)
}

\author{
B. NOLL, J. KRAPPE, B. GÖKE,* and B. MAISCH
}

From the Department of Internal Medicine, University Marburg, FRG, and *Department of Physiology, University of Michigan, Medical School, Ann Arbor, Michigan, USA

NOLL, B., ET AL.: Influence of Pacing Mode and Rate on Peripheral Levels of Atrial Natriuretic Peptide (ANP). The effect of acute modifications of pacing mode and rate on plasma ANP levels was evaluated. ANP was determined in ten resting patients with DDD pacemakers due to binodal disease or intermittent second- and third-degree AV block. At 82/minute pacing rate the ANP plasma levels (normal range 2 to 30 $\mathrm{fmol} / \mathrm{mL}$ ) corresponded to those under AAI $(4.05 \pm 2.10 \mathrm{fmol} / \mathrm{mL})$ and DDD $(4.18 \pm 2.02 \mathrm{fmol} / \mathrm{mL}) \mathrm{pacing}$, but increased significantly $(P<0.05)$ during VVI pacing $(6.96 \pm 3.70 \mathrm{fmol} / \mathrm{mL})$. Acceleration of DDD stimulation frequency from 82 to 113/minutes led to significant increases of ANP levels by the factor of three in all chosen AV delays. The lowest ANP plasma levels were measured at $175 \mathrm{msec} A V$ delay under $82 /$ minute pacing rate in DDD mode. Under 113/minutes the differences of ANP concentration after variations of $A V$ delays were less pronounced. The influences of altered atrial pressure and tension on ANP release are discussed to account for changes in ANP plasma levels following different modes and rates of pacemaker stimulation. (PACE, Vol. 12, November 1989)

atrial natriuretic peptide, artificial pacemaker stimulation, pacing mode, pacing rate

\section{Introduction}

The atria of the heart are important physiological sites of volume regulation. Beside working musculature and the specific conduction system, myoendocrine cells are located there that synthesize and store the atrial natriuretic peptide (ANP). ${ }^{1}$ Increases of ANP plasma levels can be elicited by atrial stretch caused by volume expansion, elevation of atrial pressure, and atrial tachycardia. ${ }^{2-4}$

The aim of the present study was to investigate the acute influence of different pacing modes, rates, and AV delays in patients with dual

\footnotetext{
Supported by grant no. RWH-493/51 from Stiftung P.E. Kempkes, Marburg, FRG.
}

Address for reprints: Bernd Noll, M.D., Dept. of Internal Medicine, University Marburg, Baldingerstr. 1, 3550 Marburg, Federal Republic of Germany.

Received May 10, 1989; revision August 2, 1989; accepted August 3, 1989. chamber pacemakers (DDD) on peripheral plasma levels of ANP. This was of interest since AV conduction disturbances lead to elevated atrial blood pressure. It was described that in the atrial pulse tracing of patients with third-degree AV block "cannon" A waves occur when the atrium contracts against a closed AV valve. ${ }^{4}$ Furthermore, it was suggested that variations in AV synchrony influence ANP plasma levels. ${ }^{5}$

\section{Methods}

Ten patients with DDD pacemakers (6 with Biotronik Diplos 04/05, [Biotronik, Lake Oswego, OR, USA] 4 with Intermedics Cosmos [Intermedics, Inc., Freeport, TX, USA]) were examined between 8 and 11 o'clock AM. The mean age of the patients was 65 years. None of them showed clinical evidence of congestive heart failure, valvular heart disease, or pulmonary disease. Three of them were treated with digitalis glycosides, two with nitrates, and none of them with diuretics. 


\section{ANP PLASMa LEUELS AT DIFFERENT PACING MODES}

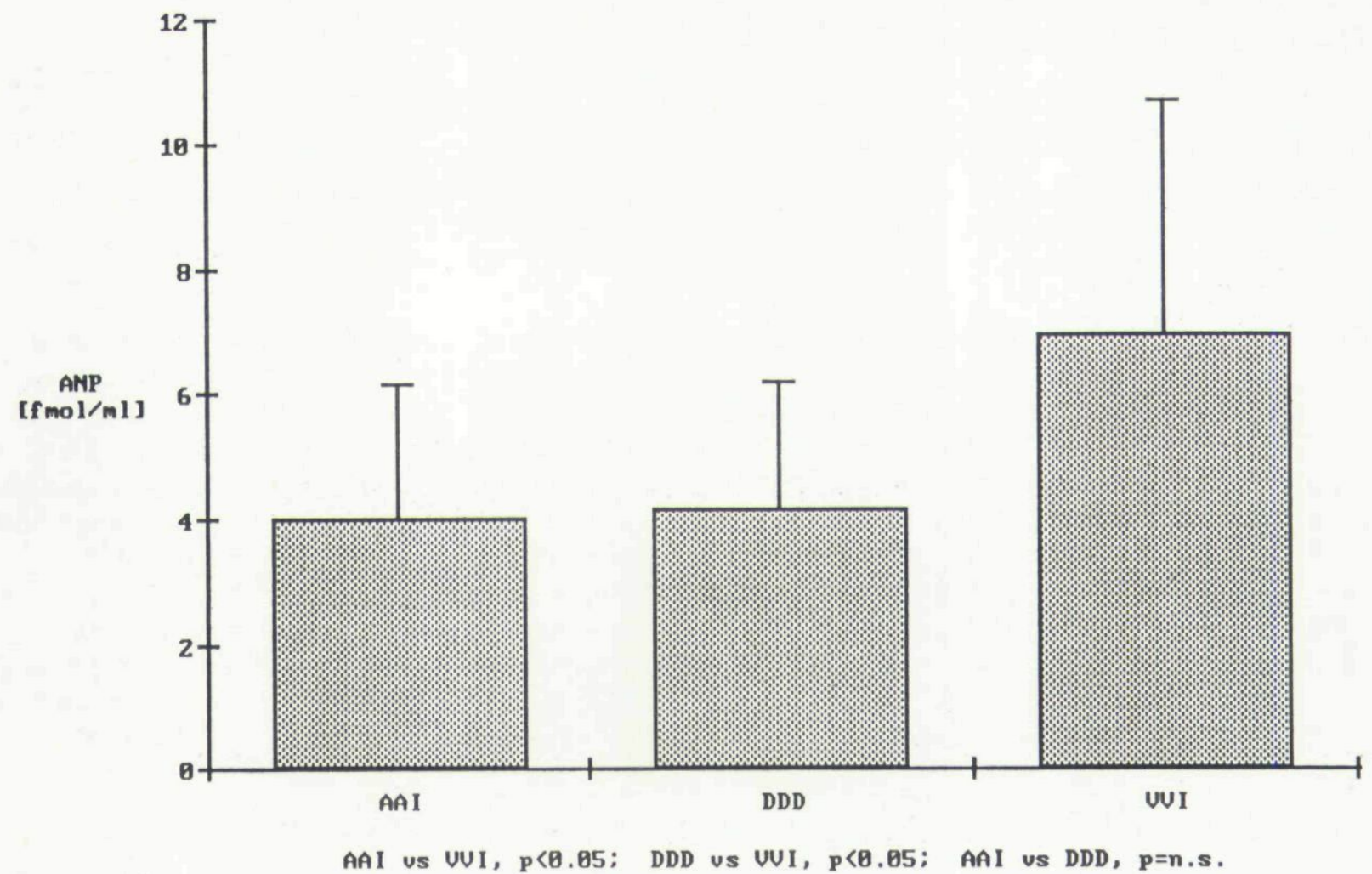

Figure 1. Mean absolute (1A) and relative (1B) ANP plasma levels during AAI, DDD, and VVI pacing at $82 /$ minute (given are means $\pm S D$ ).

The indications for pacemaker therapy were documented as intermittent second- and third-degree AV block or binodal disease in five patients, respectively.

In resting patients, the pacemakers were programmed at a rate of $82 \mathrm{bpm}$ and different AV intervals $\left(200,175,150,125,100,50\right.$, and $15^{*}$ msec) were chosen $(*$ impossible in the 4 patients with Intermedics Cosmos pacemakers). Under these conditions, the stimulation of atrium and ventricle was performed exclusively by the pacemakers. Same patients were examined 1 day later using DDD stimulation at a rate of 113 /minute and $175,150,125,100$, and 50 msec AV delay. At 200 msec AV intervals, most patients displayed ventricular combination systoles in the ECG tracing. Therefore, we did not use this AV delay. At a frequency of $113 /$ minute, the pacemakers could not be programmed in 15 msec AV delay.

The next day, ANP plasma concentrations of these patients were examined under AAI, DDD (175 msec AV delay) and VVI stimulation at 82/ minute pacing rate.

Ten minutes after switching to another AV delay or changing the pacing mode, blood was saved from an antecubital vein. Plasma ANP was measured as previously described. ${ }^{6}$ In brief, blood samples were collected on ice into EDTA tubes containing $500 \mathrm{kU} / \mathrm{mL}$ of the protease inhibitor aprotinin (Trasylol, Bayer AG, Leverkusen, FRG). After centrifugation at $2000 \mathrm{~g}$ at $4^{\circ} \mathrm{C}$ for $30 \mathrm{~min}$ utes, ANP was extracted using C18-Sep-pak cartridges (Waters Associates, Milford, MA, USA). Eluates were stored at $-70^{\circ} \mathrm{C}$ until assay. ANP was measured using a specific radioimmunoassay method (Amersham, human $\alpha$ ANP [I 125] radioimmunoassay system, code RPA.512).

Results are given as absolute ANP plasma levels during the respective AV delays or pacing modes. Relative changes in ANP concentration 


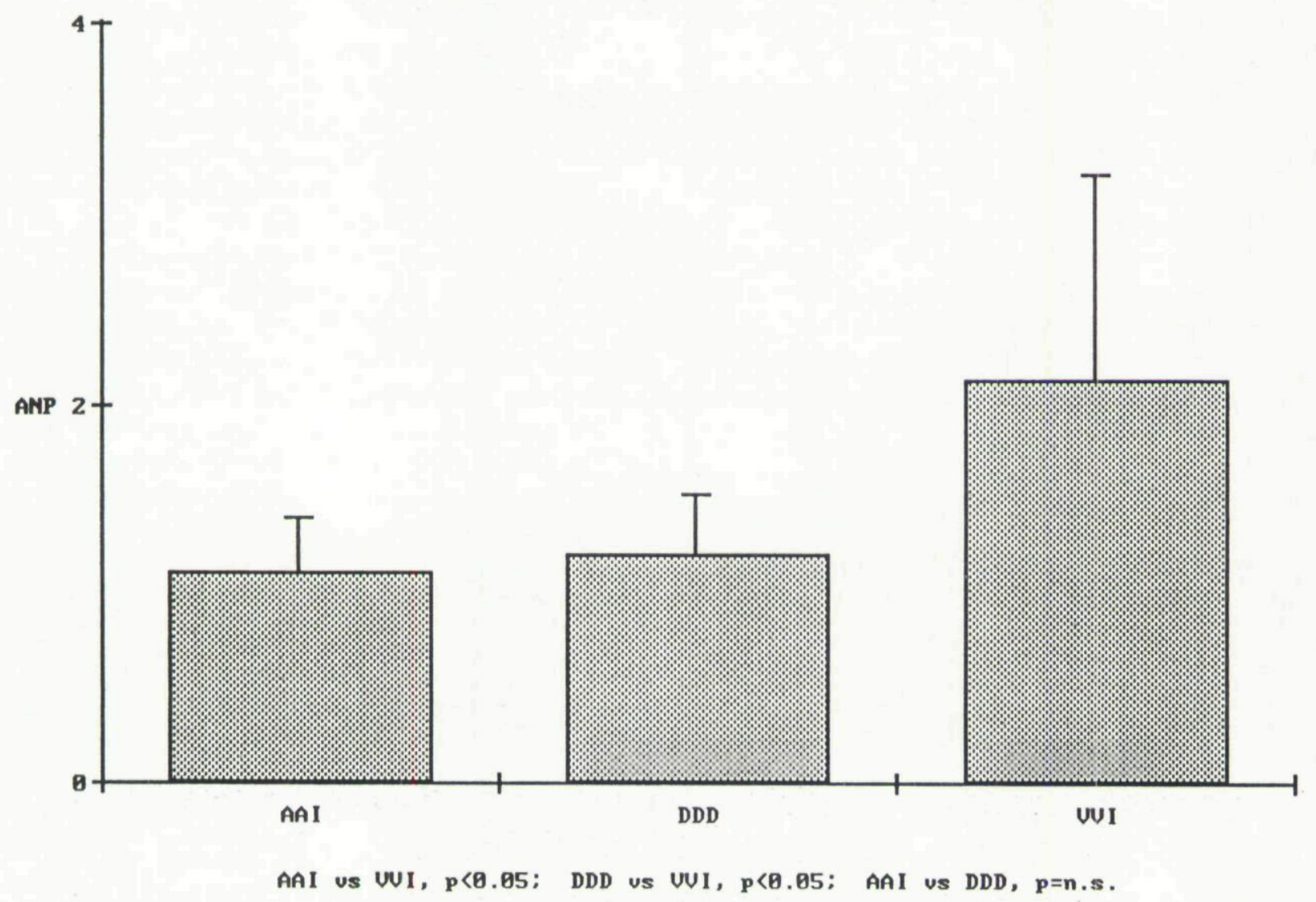

Figure 1. Continued

were calculated in comparison to basal levels which were assumed to be $=1$.

Statistical analysis was performed using oneway analysis of variance and Student's t-test for repeated measurements. Differences at the 95\% level were considered significant. All values are means \pm standard deviation (SD).

\section{Results}

The mean absolute and relative ANP plasma levels during AAI, DDD, and VVI pacing at 82/ minute are shown in Figure 1. In our resting patients, VVI stimulation caused a significant increase of circulating ANP compared to DDD and AAI pacing. There was no difference in ANP between AAI and DDD pacing mode. ANP levels were also altered by changing the programmed AV delay in DDD pacing (Table I).

At $82 /$ minute pacing rate, lowest ANP plasma concentration were measured at $175 \mathrm{msec}$ AV delay. Both extending and shortening the AV delay caused an increase of ANP. At $15 \mathrm{msec}$ AV

Table I.

ANP Plasma Levels During DDD Pacing at a Rate of $82 /$ minute at Various AV Delays

\begin{tabular}{cccr}
\hline $\begin{array}{c}\text { AV Delay } \\
\text { [msec] }\end{array}$ & $\begin{array}{c}\text { Absolute ANP } \\
\text { Plasma Levels } \\
\text { [fmol/mL] }\end{array}$ & $\begin{array}{c}\text { Relative ANP } \\
\text { Plasma Levels }\end{array}$ & $\mathbf{n}$ \\
\hline 15 & $6.761 \pm 2.930$ & $2.657 \pm 1.570$ & 6 \\
50 & $4.794 \pm 2.267$ & $1.617 \pm 0.518$ & 10 \\
100 & $4.128 \pm 1.020$ & $1.504 \pm 0.505$ & 10 \\
125 & $4.024 \pm 0.970$ & $1.440 \pm 0.391$ & 10 \\
150 & $3.843 \pm 1.438$ & $1.307 \pm 0.308$ & 10 \\
175 & $3.555 \pm 1.491$ & $1.201 \pm 0.228$ & 10 \\
200 & $3.991 \pm 1.622$ & $1.367 \pm 0.336$ & 10 \\
\hline
\end{tabular}


intervals, the elevation of ANP was statistically significant compared to the others. Programming this short AV delay led to hormone concentrations comparable to those under VVI stimulation.

At $113 /$ minute stimulation frequency, both the mean plasma ANP levels (Fig. 2) as well as those of the respective AV delays (Table II) were more than threefold higher than under $82 /$ minute.

The ANP level at a $50 \mathrm{msec}$ AV delay was above those resulting from all other AV delays. In contrast to the results described above a definite minimum of absolute or relative ANP plasma levels at certain AV intervals could not be found under $113 /$ minute.

\section{Discussion}

Myoendocrine cells located in both atria and ventricle of the heart synthesize the atrial natri- uretic peptide and store it as a prohormone of 126 amino acids. The C-terminal part of 28 amino acids contains the biologically active part of the molecule. ${ }^{1,7}$ Once released, ANP has a half-life of 3 minutes and leads to increased glomerular filtration, natriuresis, diuresis, and to an inhibition of aldosterone secretion and suppression of vasopressin release. ${ }^{1,8}$

Sensitive radioimmunoassay systems are now available for routine ANP measurements. Approximately 2 to $30 \mathrm{fmol} / \mathrm{mL}$ of this peptide can be measured in human plasma of healthy individuals. ${ }^{9,10}$ There is evidence for an increase of ANP plasma concentrations with age in the literature, which is thought to mirror a compensatory mechanism resulting from decreased tissue responses to ANP. ${ }^{9}$ However, the basal hormone levels in our patients, who were 65-years-old on an average, ranged from 3.5 to $17.7 \mathrm{fmol} / \mathrm{mL}$ and

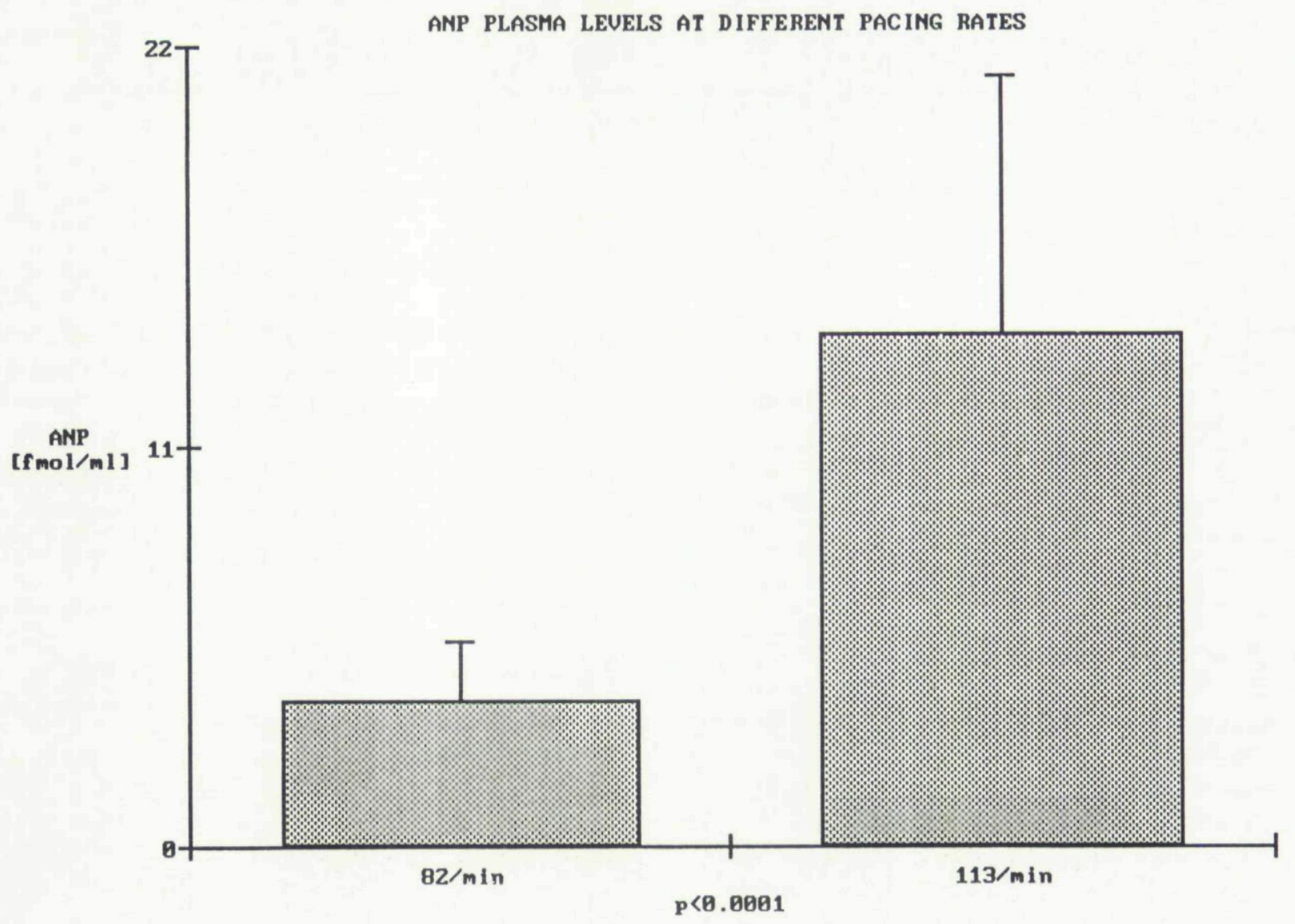

Figure 2. Mean ANP plasma levels at $82 /$ minute and $113 /$ minute pacing rate (given are means $\pm \mathrm{SD}$ ). 
were, therefore, comparable to those values previously described in younger individuals. This may be due to the lack of congestive heart failure or pulmonary disease in our patients. These diseases are often seen in aged patients and are known to elevate ANP plasma levels. ${ }^{11,12}$ However, the efficiency of the plasma extraction procedure used may be an important consideration. Our sample purification method yields about 75\% recovery of atrial natriuretic peptide. This must be taken into account when ANP concentrations reported in the literature are compared with ours.

An increase of circulating ANP is caused by atrial stretch or dilatation as well as frequent atrial pacemaker stimulation or atrial fibrillation. ${ }^{3,13-15}$ Furthermore, the pacing mode influences ANP secretion. Haufe and co-workers found that right ventricular pacing led to a pacing rate dependent increase of ANP plasma levels up to $300 \%$, whereas significant higher hormone levels under AAI pacing occurred only at pacing rates higher than $140 /$ minute $^{3}$ The authors reported a correlation between right atrial blood pressure and plasma ANP concentrations. Stangl and co-authors described higher plasma ANP in patients with third-degree AV block at rest and under bicycle ergometry during VVI pacing at $70 /$ minute compared to DDD pacing with 100 msec AV delay. ${ }^{5}$

Our data show that variations of AV delay also influence peripheral ANP plasma levels. Minimal ANP concentrations were detected at 82/minute under $175 \mathrm{msec}$ AV delay. Both shorter and longer AV intervals led to higher hormone levels. This was discussed as being due tc alterations of atrial pressure and tension. ${ }^{3,5,13}$ From animal experiments, it was reported that under conditions that allowed the atrial systole to get closer to the mechanical ventricular systole, atrial contractions against a closed AV valve occurred. These lead to elevated atrial pressure with blood regurgitation into the pulmonary veins. This caused an enlargement of the left atrial diameter. ${ }^{18,19}$ Furthermore, significant changes in cardiac output due to slight AV interval variations were reported from clinical observations. ${ }^{19}$

At a $113 /$ minute pacing rate, the differences in ANP plasma levels caused by AV delay variations were less pronounced. This higher stimulation rate led to a threefold increase of hormone
Table II.

ANP Plasma Levels During DDD Pacing at a Rate of $113 /$ minute at Various AV Delays

\begin{tabular}{cccc}
\hline $\begin{array}{c}\text { AV Delay } \\
\text { [msec] }\end{array}$ & $\begin{array}{c}\text { Absolute ANP } \\
\text { Plasma Levels } \\
\text { [fmol/mL] }\end{array}$ & $\begin{array}{c}\text { Relative ANP } \\
\text { Plasma Levels }\end{array}$ & $\mathbf{n}$ \\
\hline 50 & $17.740 \pm 8.112$ & $1.667 \pm 0.451$ & 10 \\
100 & $12.896 \pm 5.861$ & $1.176 \pm 0.224$ & 10 \\
125 & $13.413 \pm 7.335$ & $1.142 \pm 0.071$ & 10 \\
150 & $13.040 \pm 7.193$ & $1.098 \pm 0.078$ & 10 \\
175 & $13.712 \pm 7.417$ & $1.167 \pm 0.174$ & 10 \\
\hline
\end{tabular}

concentrations in all AV intervals. Therefore, since only slight changes in ANP plasma levels occurred after changing the programmed AV delay these hormone levels could not be used to define the most hemodynamically beneficial AV interval in DDD pacing at this pacing rate.

Interestingly, there were no differences in plasma ANP levels between AAI and DDD pacing. It is obvious that pacemaker stimulation of the right ventricle did not induce any relevant ANP release.

There was a statistical difference in plasma ANP between VVI and DDD pacing at 82 /minute. This result corroborates a previous report concerning the lack of AV synchrony in VVI pacing with occurrence of "cannon A waves" in the atrial pressure tracings. ${ }^{3,5}$ The "pacemaker syndrome" is believed to be based on the latter pathomechanism. ${ }^{3,16}$ Until now, it is rather speculative to hypothesize whether an increase of atrial natriuretic peptide in VVI pacing may contribute to this "pacemaker syndrome". In this context it seems of some interest to evaluate ANP levels after a prolonged pacing in the VVI mode. This is not done in the present study, but is an important matter for further research. The known direct vasodilatory effect of $\mathrm{ANP}^{17}$ together with our results after acute stimulations offers at least a rationale to design such follow-up studies.

Acknowledgments: The data were presented at the 10th Annual Scientific Session of the North American Society of Pacing and Electrophysiology 1989 in Toronto, Canada, and have appeared in abstract form [PACE 1989; 12 (Pt. 1):672]. B. Göke is a research fellow of the Deutsche Forschungsgemeinschaft (DFG; Heisenberg program). We are grateful to I. Muttschall for skillful technical assistance. 


\section{References}

1. Needleman P, Greenwald JE. Atriopeptin: A cardiac hormone involved in fluid, electrolyte, and blood-pressure homeostasis. N Engl J Med 1986; 314:828-834.

2. Crozier IG, Nicholls MG, Ikram H, et al. Relation between left atrial diameter and plasma atrial natriuretic peptide, renin and vasopressin. Am J Cardiol 1986; 58:1134-1136.

3. Haufe MC, Weil J, Nafzger K, et al. Acute increase in right atrial pressure by intracardiac stimulation releases atrial natriuretic peptide. Eur Heart J 1987; 8:277-281.

4. Craige E, Smith D. Heart sounds: Phonocardiography; carotid, apex, and jugular venous pulse tracings; and systolic time intervals. In E Braunwald (ed.): Heart Disease. Philadelphia, WB Saunders, 1988, pp. 41-64

5. Stangl K, Weil J, Seitz K, et al. Influence of AV synchrony on the plasma levels of atrial natriuretic peptide (ANP) in patients with total AV block. PACE 1987; 11:1176-1181.

6. Riegger GAJ, Elsner D, Kromer EP, et al. Atrial natriuretic peptide in congestive heart failure in the dog: Plasma levels, cyclic guanosine monophosphate, ultrastructure of atrial myoendocrine cells, and hemodynamic, hormonal, and renal effects. Circulation 1988; 77(2):398-406.

7. Forsmann WG. Cardiac hormones. I. Review on the morphology, biochemistry, and molecular biology of the endocrine heart. Eur J Clin Invest $1986 ; 16: 439-451$.

8. De Bold AJ, Borenstein HB, Veress AT, et al. A rapid and potent natriuretic response to intravenous injection of atrial extracts in rats. Life Sci 1981; 28:89-94.

9. Ohashi M, Fujio N, Nawata H, et al. High plasma concentrations of human atrial natriuretic polypeptide in aged men. J Clin Endocr 1987; 64:81-85.
10. Pastan SO, Braunwald E. Renal disorders and heart disease. In E Braunwald (ed.): Heart Disease. Philadelphia, WB Saunders, 1988, pp. 1828-1847.

11. Anderson JV, Woodruff PWR, Bloom SR. The effect of treatment of congestive heart failure on plasma atrial natriuretic peptide concentration. $\mathrm{Br}$ Heart J 1988; 59:207-211.

12. Goetz KL. Physiology and pathophysiology of atrial peptides. Am J Physiol 1988; 254:E1-E15.

13. Matsubara H, Nishikawa M, Umeda Y, et al. The role of atrial pressure in secreting atrial natriuretic polypeptides. Am Heart J 1987; 113:14571463.

14. Roy D, Paillard D, Cassidy D, et al. Atrial natriuretic factor during atrial fibrillation and supraventricular tachycardia. J Am Coll Cardiol 1987; 9:509-514.

15. Schiebinger RJ, Linden J. Effect of atrial contraction frequency on atrial natriuretic peptide secretion. Am J Physiol 1986; 251:H1095-H1099.

16. Alicandri C, Fouad FM, Tarazi RC, et al. Three cases of hypotension and syncope with ventricular pacing: possible role of atrial reflexes. Am J Cardiol 1978; 42:137-142.

17. Faison EP, Siegl PKS, Morgan G, et al. Regional vasorelaxant selectivity of atrial natriuretic factor in isolated rabbit vessels. Life Sci 1985; 37:10731079.

18. Naito M, Dreifus LS, Mardelli TJ, et al. Echocardiographic features of atrioventricular and ventriculoatrial conduction. Am J Cardiol 1980; 46:625-633.

19. Thormann J, Schlepper M. Hämodynamische Auswirkungen kardialer Arrhythmien. In B Lüderitz (ed.): Handbuch der inneren Medizin. Berlin-Heidelberg-New York: Springer, 1983, pp. 355-421. 
This document is a scanned copy of a printed document. No warranty is given about the accuracy of the copy. Users should refer to the original published version of the material. 